\title{
Osteopenia in Premature Infants and Effect of Supplementation
}

\author{
NADIRAAFROZ ${ }^{1}$, MAKAZAD CHOWDHURY², MD. MAHBUBUL HOQUE ${ }^{3}$, DILDER AHMED KHAN ${ }^{4}$
}

\begin{abstract}
Background: Despite advances in antenatal and prenatal care, incidence of preterm labor is still high. Osteopenia of prematurity is one of the common accompaniments or complications of surviving preterm babies. Most of the time this problem remains hidden, so is untreated by most of the physicians which leads to growth retardation, delayed bone maturation, fractures with minimal trauma and other complications in infancy.

Objective: This study was an attempt to see osteopenia in preterm babies admitted in hospital and to see the effect of supplementation with calcium and phosphorus on those babies and to corelate serum calcium and phosphorus level with gestational age and bone density.

Methods: A total 96 of preterm babies admitted in Dhaka Shishu (Children) Hospital (DSH) and Maternal \& Child health Training Institute (MCHTI) of either sex were selected randomly during the period of January 2005 to June 2006. Venous blood was tested for serum calcium and phosphorus level and X-ray of lower limb to see bone density. All cases were given calcium $200 \mathrm{mg} / \mathrm{kg} /$ day and phosphorus $90 \mathrm{mg} / \mathrm{kg} /$ day with multivitamin drop of 6 drops/day up to 3 months of age.

Result: Out of 96 preterm babies 27 had osteopenia with male preponderance [67\%]. Gestational ages were between $28-32$ weeks and in $78 \%$ cases weight were with 1000-1500 gm. Most of the mothers were 18-25 years and housewives. Initial mean serum calcium level was $1.66 \mathrm{mmol} / \mathrm{l}$ and phosphorus level was $1.58 \mathrm{mmol} / \mathrm{l}$. After 3 months of supplementation, it was $2 \mathrm{mmol} / \mathrm{l}$ and $2.08 \mathrm{mmol} / \mathrm{l}$ respectively. Serum alkaline phosphatase was initially 736.6 and follow up level after 3 months was 353.14. Weight also increased, it was [mean] $3448 \mathrm{~g}$ whereas initial weight was $1277 \mathrm{gm}$. There was significant reduction of alkaline phosphatase during the 3 months $[P<0.05]$.

Conclusion: Prevalence of osteopenia is high (28\%) in premature infants. Less the gestational age more the chance of osteopenia. Calcium and Phosphorous supplementation has showed very good effect to achieve normal growth pattern.
\end{abstract}

Key words: Premature baby, osteopenia, calcium and phosphorus.

\section{Introduction}

Incidence of preterm labor, premature and low birth weight babies is high in our country which is about 36 $\% .^{1}$ Due to advanced treatment facilities preterm babies survived more than past. These Premature babies who survive needs special attention as they may develop complications like osteopenia, which leads to growth retardation, delayed bone maturation, fractures with minimal trauma and other complications

1. Junior Consultant, Dept of Pediatrics, Maternal \& Child health Training Institute, Azimpur, Dhaka.

2. Professor of Neonatalogy, Dhaka Shishu (Children) Hospital, Dhaka.

3. Associate Professor of Neonatalogy, Dhaka Shishu (Children) Hospital, Dhaka.

4. Senior Consultant, Dept. of Pediatrics, Maternal \& Child health Training Institute, Azimpur, Dhaka.

Correspondence: Dr. Nadira Afroz. in infancy. Most of the previous studies reported the incidences of osteopenia of prematurity was as high as up to $25-75 \%{ }^{2,3}$

Osteopenia of prematurity refers to the hypomineralized skeleton of the premature infant compared to that of the normal fetal skeleton resulting from inadequate in-utero accretion of minerals. Their bone mineral content at term corrected age has been found to be $25-70 \%$ lower than in term. ${ }^{4}$ In very low birth weight infants (birth wt $<1500 \mathrm{gm} \&$ gestational age $<32$ wks), it occurs almost without exception. This is not surprising considering that about $80 \%$ of fetal skeletal mineralization takes place during the last trimester of pregnancy. Thus one would expect increasing degree of osteopenia in premature infants with decreasing gestational age. It has been observed 
that about $20-32 \%$ of infant with birth weight $<1500$ gm have fracture and with birth weight. less than 1000 $\mathrm{gm}$, it is about $50-60 \%$. Prevalence of osteopenia in preterm babies between 34-36 wks of gestational age is not clearly available. Osteopenia is expected to be higher in preterm, low birth weight babies in our country because of the factors like high incidence of small for gestational age babies, poor ante-natal care, inappropriate post-natal feeding of these neonates without any supplementation and also feeding mismanagement. In addition to nutritional factors, several neurological \& mechanical factors increase risk for developing osteopenia of prematurity. Preterm babies are hypotonic and require longer period of immobilization which predispose to osteopenia. 5,6

Fetal accretion of calcium has been estimated to increase from $130 \mathrm{mg} / \mathrm{kg}$ per day at $28 \mathrm{wks}$ gestation to as high as $150 \mathrm{mg} / \mathrm{kg}$ per day at 36 wks gestation. ${ }^{7}$ Maintaining this intrauterine accretion rate of minerals after birth has been one of the challenging tasks in neonatology, and the failure to achieve skeletal retention of Calcium and Phosphorus equal to the intrauterine rate is the most important factor in the etiology of osteopenia. Maternal deficiency of vitamin $D$ as well as toxemia of pregnancy may contribute to the development of osteopenia in infants due to reduced supply of Calcium, Phosphorus \& vitamin D to the fetus. ${ }^{8}$ The fetal demand for Calcium progressively increases during the course of pregnancy starting from $7 \mathrm{mg} / \mathrm{dl}$ to as much as $350 \mathrm{mg} / \mathrm{dl}$ near term. It appears that major cause of osteopenia in very low birth wt infants receiving adequate daily vitamin $D$, supplementation is deficiency of Calcium \& Phosphorus. This problem is present even in the stable, relatively healthy, growing premature infant. For these infants, mothers' milk containing $25-35 \mathrm{mg} /$ dl of Calcium \& $10-15 \mathrm{mg} / \mathrm{dl}$ of phosphorus simply does not contain enough minerals to support skeletal growth at the intrauterine rate, even assuming $100 \%$ retention. Preterm human milk does not contain appreciably more of these minerals. So supplementation is required. Following preterm birth, mineral accretion is decreased relative to the increase in bone length and skeletal growth, resulting in decreased bone mineral apparent density and bone mineral content at corrected term gestational age. ${ }^{9}$ Serum alkaline phosphatase, serum calcium and serum inorganic phosphates have been suggested to be a way of identifying preterm infant with osteopenia of prematurity. ${ }^{10}$ With this view this study was conducted to see the prevalence of osteopenia in preterm babies and to see the effect of supplementation with calcium and phosphorous.

\section{Materials and Methods}

The longitudinal observational study was done from January 2005 to June 2006 in the department of Neonatology of Dhaka Shishu hospital \& Maternal and Child Health Training Institute. Premature baby of 28 -35 wks of gestation were included in the study. Babies with gross congenital anomaly or severe birth asphyxia or history of chronic illness of mother, or drugs like frusemide, aldectone, aminophylline, phenobarbitone were excluded. Gestational age assessments was done by history of LMP \& or by New Ballard score. All cases were managed according to unit protocol. After initial stabilization of the patient, blood samples for serum Calcium, phosphorus, alkaline phosphatasewere taken at around 10-14 days of age. X-ray of lower limbs was taken at that time to identify osteopenia. This investigation was done in the Biochemistry \& Radiology Department of Dhaka Shishu Hospial, and in Maternal and child health training institute. Babies were given breast milk when tolerated. Some babies were given formula milk whose mothers were not present with baby. Osteopenia was defined by X-Ray evidence of bone demineralization \& elevated level of alkaline phosphatase $(>600)$. XRay evidence of bone demineralization in preterm with osteopenia was graded as follows: Grade I:Loss of dense white line of metaphysis with increased submetaphyseal lucency and thinning of cortex. Grade II: Changes of grade 1 with irregularity, fraying, splaying and cupping of metaphysis. Grade III: Changes of grade II and evidence of fracture. ${ }^{11-13}$ Measuring osteopenia by bone densitometry is also good method of assessing bone maturity. Unfortunately we could not do it due to high cost. So this prospective study was designed to assess the osteopenia in preterm baby by using biochemical and radiological parameter.

Those who had positive finding for osteopenia, supplemented by Calcium-Phosphorus solution, started from the age of 14 days. All cases were given Calcium-200 mg /Kg/day,Phosphorus- $90 \mathrm{mg} / \mathrm{Kg} /$ day ${ }^{14,15}$ \& multivitamin drop 6drops/day. Bham \& company prepared the Calcium \& Phosphorus solution. After preparation, it was tested for sterility two times in Medinova Laboratory.

Patients were followed up at $4,8 \& 12$ weeks of their age. In follow up length , weight, OFC and biochemical parameter were assessed.

\section{Results}

A total of 96 preterm patients were studied. Out of them, 27 patients had osteopenia. Among the osteopenic babies, male were $67 \%$ and female were $33 \%$. Most of the babies (66\%)were within 28-32 wks of gestational age. Seventy- eight percent babies were 1000-1500 gm, $15 \%$ were $<1000 \mathrm{gm} \& 7 \%$ were $1500-2000 \mathrm{gm}$ (Table-I). 
BANGLADESH J CHILD HEALTH 2015; VOL 39 (3) : 137

Table-I

Demographic distribution of preterm babies with osteopenia

\begin{tabular}{lcc}
\hline Characteristics & Number & Percentage \\
\hline Gestational Age & & \\
28-32 weeks & 17 & $67 \%$ \\
32-36 weeks & 10 & $33 \%$ \\
Sex distribution & & \\
$\quad$ Male & 18 & $67 \%$ \\
$\quad$ Female & 9 & $33 \%$ \\
Maternal Age (Yrs) & & \\
$\quad<18$ & 5 & $19 \%$ \\
18-25 & 16 & $59 \%$ \\
$\quad>25$ & 6 & $22 \%$ \\
Weight (gm) & & \\
$\quad 1500-2000$ & 3 & $7 \%$ \\
$1000-1500$ & 20 & $78 \%$ \\
$<1000$ & 4 & $15 \%$ \\
\hline
\end{tabular}

Sixty seven (67)\% were within 32 weeks gestation $78 \%$ were VLBW.

Biochemical Parameters- Initial mean serum calcium level was $1.66 \mathrm{mmol} / \mathrm{L}$, after 3 month it became 2mmol/L (Fig.-1).

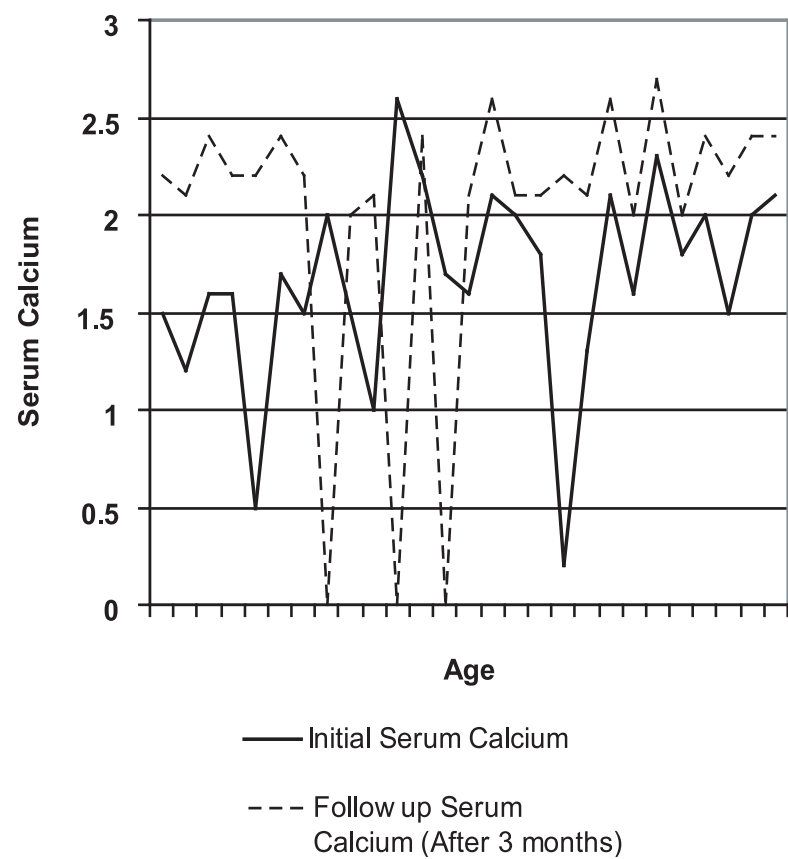

Fig.-1: The mean initial and follow-up values of serum calcium in all 27 cases.
Osteopenia in Premature Infants and Effect of Supplementation

Mean serum phosphorus level was $1.58 \mathrm{mmol} / \mathrm{L}$ initially and it was $2.08 \mathrm{mmol} / \mathrm{L}$ after 3 month (Fig.-2).
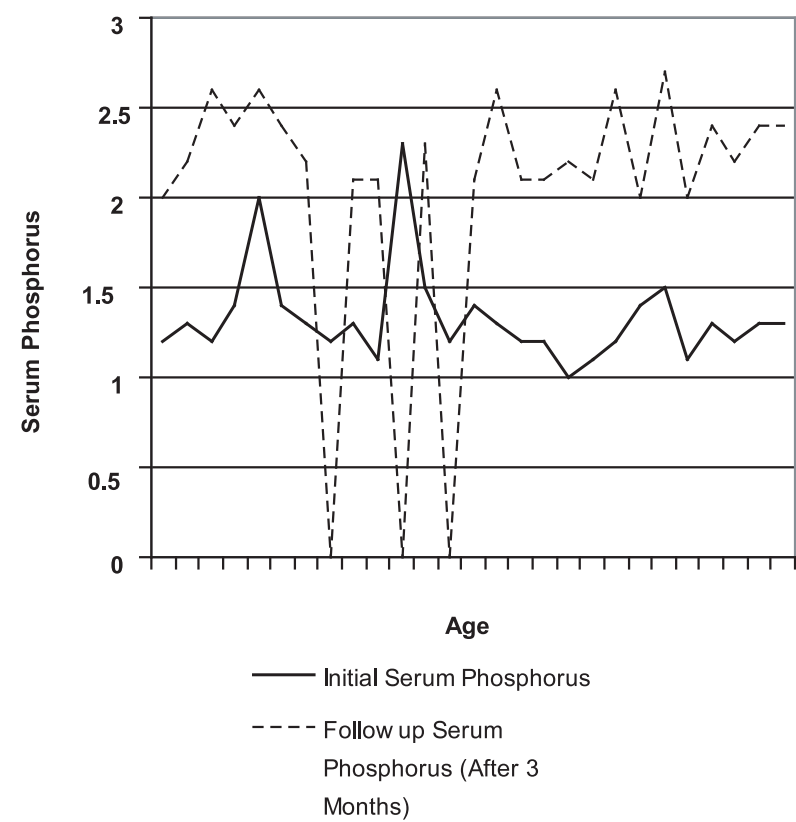

Fig.-2: The mean initial and follow-up values of serum Phosphorous in all 27 cases.

Serum alkaline phosphatase level was 736.6 initially \& follow up level after 3 month was 353.14. (Fig.-3)

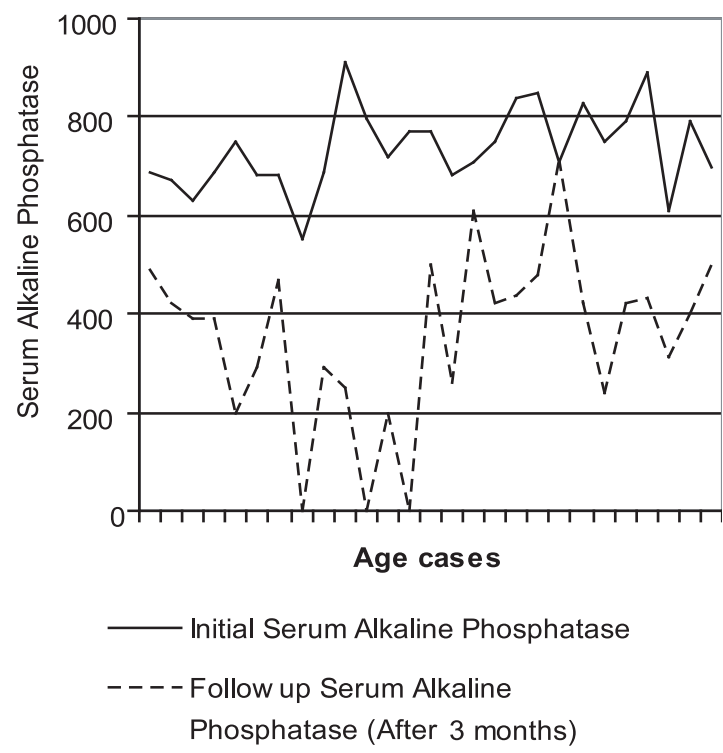

Fig.-3: The mean initial and follow-up values of serum Alkaline Phosphatase in all 27 cases.

The serum alkaline phosphstase values decreases with increases of age. Less the gestational age more the alkaline phosphatase level( $p=.048)($ Table-II). 
Table-II

Relation of alkaline phosphatase of osteopenia babies according to their gestational age

\begin{tabular}{lccc}
\hline & $G$ age of babies $(\leq 30$ weeks $)$ & $G$ age of babies $(>30$ weeks $)$ & $P$-value \\
\hline Al Phosphatase (mean $\pm S D)$ & $748.363 \pm 84.216$ & $664.600 \pm 67.222$ & $P=0.048$ \\
\hline
\end{tabular}

ALP level was significantly higher in osteopenia babies of gestational age less than 30 weeks those who are more than 30 weeks of gestational age.

Mean calcium level was directly proportionate to the weight of the babies $(p=0.02)$ (Table -III).

Table-III

Distribution of initial calcium level of osteopenia babies according to their initial weight

\begin{tabular}{lccc}
\hline & Weight of babies & Weight of & $P_{-}$ \\
& $(\leq 1.20)$ & babies $(>1.20)$ & value \\
\hline Initial calcium & $0.64 \pm 0.494$ & 0.850376 & $P=0.02$ \\
(mean $\pm S D)$ & & & \\
\hline
\end{tabular}

$\mathrm{P}$-value reached from unpaired " $\mathrm{t}$ " test.

$\mathrm{P}<0.020$ significant.

Initial mean calcium level was significantly low in babies' weighting less then $1.2 \mathrm{~kg}$ than babies who were more than $1.2 \mathrm{~kg}$.

Growth Parameters - Initial mean weight of preterm babies was $1277 \mathrm{gm}$ and it became $3448 \mathrm{gm}$ after 3 month (Fig.-4).

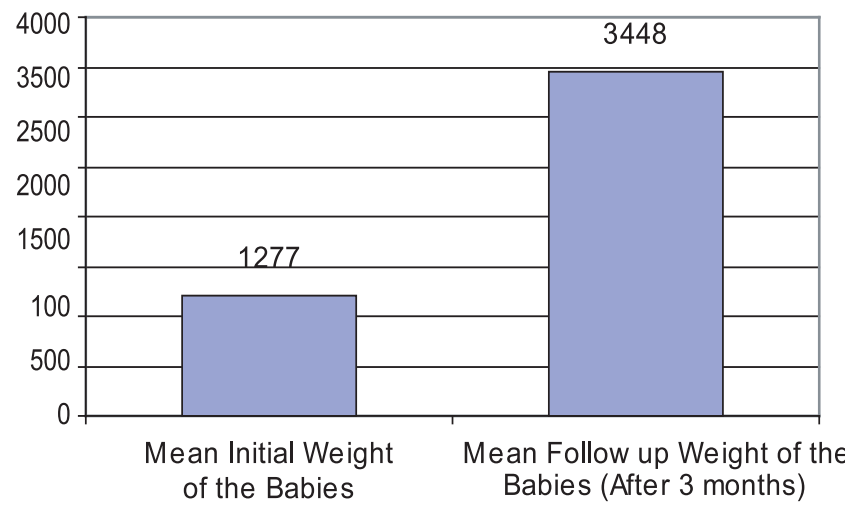

Fig.-4 : Bar chart showing mean distribution of weight (initial birth and follow-up after three months) of osteopenia of preterm babies.
This weight gain was higher compare to growth chart (Fig.-5).

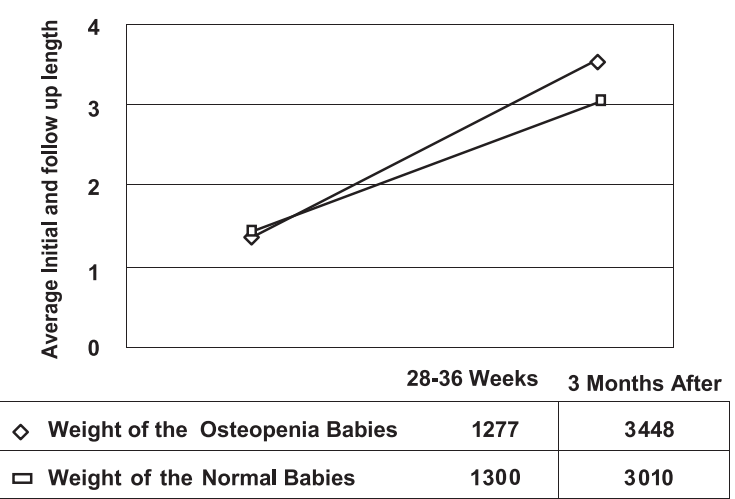

Fig.-5: Comparison of wt of study case with growth chart of normal babies at 3 month.

Length was initially $39.49 \mathrm{~cm}$ and 3 months after follow up it became $50.88 \mathrm{~cm}$ (Fig.-6).

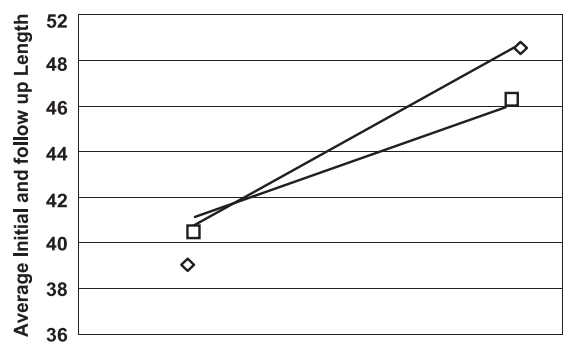

\begin{tabular}{|l|c|c|}
\hline & $28-36$ Weeks & 3 Months After \\
\hline$\diamond$ Length of the Osteopenia Babies & 39.2 & 50.8 \\
\hline$\square$ Length of the Normal Babies preterm. & 41.0 & 46.0 \\
\hline
\end{tabular}

Fig.-6: Comparison between average length of normal babies at three month and follow up (after $3 \mathrm{mo}$ ) of Osteopenia of preterm babies.

The above figure shows weight of preterm babies whose mean weight initially was 1277 and the follow up weight was 3448 . The mean value of weight follow up increases.

According to Radiological finding, 25 out of 27 osteopenic patient had grade- 1 features and 2 cases had grade-2 features. No cases had grade- 3 findings. 


\section{Discussion}

Prematurity and low birth weight is much higher (about $30-50 \%$ ) in Bangladesh. One of the common problems of prematurity is inadequate mineralization and growth of the bones (osteopenia), leading to subclinical and clinical fractures and improper growth of the babies. This study was done to find out the prevalence of osteopenia in preterm babies and to see the effect of supplementation with calcium and phosphorous.

Preterm babies without major congenital anomalies delivered or attaining two hospital were analyzed. Total 96 babies were studied. Osteopenia was found in $27(28 \%)$ babies on the basis of biochemical and radiological findings. The male to female 2:1. (Male were $67 \%$ \& female- $33 \%$ ). Our study showed that degree of osteopenia is directly related to degree of prematurity. In our study sixty seven percent babies were of less than 32 weeks of gestation and majority of the babies $(78 \%)$ were of birth weight between 1000 $1500 \mathrm{gm}$. Other studies showed the similar findings of osteopenia in relation to gestational age and weight of the babies. Catch et al and Backstorm found in their study that mean wt and gestational age of osteopenic babies were $1255.39 \pm 181.7$ gestational age $31.62 \pm 2.15 .{ }^{16,17}$ Gestational age is an important factor. The less the gestational age, more the baby develop osteopenic feature.

All (28\%) the osteopenia babies were supplemented with calcium (200 mg/kg/day) and phosphorus (90 $\mathrm{mg} / \mathrm{kg} /$ day) along with multivitamin drop (for vit D)and were followed upto 3 months. Only few patient had side effect of vomiting without dehydration. They grew adequately with their length and weight. Their mean weight after 3 month was $3448 \mathrm{~kg}$ and mean length $50.8 \mathrm{~cm}$, which showed their adequate growth in comparison to standard growth chart. ${ }^{18}$

The risk of developing feature of osteopenia is more in less gestational age and less body weight. After 3 month of supplementation the value of serum calcium and serum phosphorus raises from $1.59 \mathrm{mmol} / \mathrm{L}$ to 2.12 and $1.58 \mathrm{mmol} / \mathrm{L}$ to 2.08 respectively. ALP level decreases from 732.85 to 377.96 after 3 months.

Radiologically 25 cases had in grade-I features of osteopenia, 2 cases were grade-II. None were in grade III. In 1989, Koo et al ${ }^{17}$ conducted a prospective study of 78 very low birth weight infants, observed $30 \%$ incidence of fracture/rickets in first 1 year of life. Mitchell et al selectively screened 32 extremely low birth weight infants with ALP level > $800 \mathrm{IU} / \mathrm{L}$ for radiological rickets. All had evidence of osteopenia and 18/32 (56\%) had radiological rickets. ${ }^{19,20}$ Out of 27 preterm cases 2 babies died. One due to extreme prematurity (wt $725 \mathrm{gm}$ of birth $\mathrm{wt}$ ) and another died at the age of one \& half month of age possibly due to sepsis. The study populations were selected purposively from a selected hospital of the country. The finding might be area specific and might not necessarily represent national situation.

There was no control group (without supplementation) to compare the growth with the supplemented case. Bone densitometry could not be done. Radiation hazards of X-Ray could not be avoided in infants.

\section{Conclusion}

Prevalence of osteopenia is high (28\%) in premature infants. Radiological evidence of osteopenia was directly proportional to the degree of gestational age. Serum phosphate was significantly low in infants with osteopenia. Calcium and Phosphorous supplementation has showed very good effect to achieve normal growth pattern.

\section{Recommendation}

With the help of biochemical and radiological parameter we can easily diagnose osteopenia of preterm babies and counsel the parents about the complications and how to overcome the problem early.

\section{References}

1. National low birth weight survey of Bangladesh, 2003-2004, Monitoring the Situation of children \& Women project, Bangladesh Bureau of Statistics, with assistance from Unicef, Dhaka. BBS and UNICEF. 2005. P. 39.

2. Crofton PM, Shrivastava A, Wade JC, Stephen $\mathrm{R}$, Kelnar CJ, Lyon AJ, et al. Bone and collagen markers in preterm infants: relationship with growth and bone mineral content over the first 10 weeks of life. Pediatr Res. 1999;46: 581-87.

3. Lyon AJ, Mclntosh N, Wheeler K, Williams JE. Radiological rickets in extremely low birth weight infants. Pediatr Radiol. 1987;17:56-58.

4. HorsmanA, Ryan SW, Congdon PJ, Truscott J $G$ and James J R. Osteopenia in extremely low birth weight infants. Arch Dis Child.1989;64: 485-88. 
5. Mora S,Weber G, Bellini A,Bianchi C, Chiumello G.Bone modeling aleration in premature infants. Arch Pediar Adolesc Med. 1994;148:1215-17.

6. Bandara S, Amila K. Incidence of osteopenia of premaurity in preterm infants who were exclusively fed breast milk. Early Human Development. 2010;86:S18.

7. Vachharajani AJ, Amit M. Mathur and Rakesh Rao. Metabolic Bone Disease of Prematurity. Neo Reviews. 2009;10:e 402-e411.

8. Rohana J, Hasmawati J, Zulkifli SZ. Risk factors associated with low bone mineral content in very low birth weight infants. Singapore Med J. 2007;48:191-94.

9. Weisman $Y$, Harell A, Edelstein S, David M, Spirer Z, Golander A. 1 alpha,25Dihydroxyvitamin D3 and 24, 25- dihydroxy vitamin D3 in vitro synthesis by human deciduas and placenta. Nature. 1979;281:317.

10. Faerk J, peitersen B, Petersen S, Michaelsen $\mathrm{KF}$. Bone mineralization in premature infants cannot be predicted from serum alkaline phosphatase, or serum phosphate. Arch Dis Child Fetal Neonatal Ed. 2002;87:F133-F136.

11. Koo WW Gupta JM Nayanar VV, Wilkinson M and Posen S Skeletal changes in preterm infants. Arch Dis Child. 1982;57:447-52.

12. Koo WWK, Tsang RC. Calcium and Magnesium Homeostasis. In: Avery GB, Fletcher MA, MAcDonalds MG, editors. Neonatology Pathophysiology and management of the new born. $5^{\text {th }}$ ed. Published in 1999.pg:731-32.

13. Abrams SA. Osteopenia of Prematurity. In: Cloherty JP, Wald ECE, Hansen ARI, Stark AR, editors. Manual of the neonatal care. $5^{\text {th }}$ ed. Published in 2004.P.762-63.
14. Gomella TL. Disorder of Calcium \& Magnesium Metabolism. In: Gomella TL, Cunningham MD, FG Eyail, Karin E Xenk, editors. Neonatology, Management, Procedures, on call problems, Diseases and drugs. $5^{\text {th }}$ ed. published in 1999. P. 563-65.

15. Forfar \& Arneil's, Neonatal Metabolic Disorders, Forfar \& Arneil's, Neil MC, Peter J Helms, Rosalind, editors in Textbook of Pediatrics. $6^{\text {th }}$ ed. Published in 2003. P 366.

16. Backstrom MC, Kouri T, Kuusela AL, Sieva"nen $\mathrm{H}$, Koivisto A-M, Ikonen RS et al. Bone isoenzyme of serum alkaline phosphatase and serum inorganic phosphate in metabolic bone disease of prematurity. ActaPediatrica. 2000;89: 867-73.

17. Catache M, Leone CR. Role of plasma and phosphorus measurement early detection of phosphorus deficiency in very low birth weight infants. Acta Paediatr. 2003;92:76-80.

18. Gomella TL, Cunningham MD, FG Eyal MD, Karin E Zenk. Neonatology- Management, Procedures, on call problems, Diseases and drugs. $5^{\text {th }}$ ed. Published in 1999. Page no -675.

19. Mitchell SM, Rogers SP, Hicks PD, Hawthorne KM, Parker BR, Abrams SA. High frequencies of elevated alkaline phosphates activity and rickets exist in extremely low birth weight infants despite current nutritional support. BMC Pediatrics. 2009;9:1-7.

20. Mazess RB, Peppler WW, Chesney RW, Lange TA, Lindgren U, Smith E Jr. Does bone measurement on the radius indicate skeletal status? Concise Communicaion. Jnucl Med. 1984; 25:281-88. 